\title{
Clinicopathological significance of the gene expression of matrix metalloproteinases and reversion-inducing cysteine-rich protein with Kazal motifs in patients with colorectal cancer: MMP-2 gene expression is a useful predictor of liver metastasis from colorectal cancer
}

\author{
TAKASHI OSHIMA ${ }^{1}$, CHIKARA KUNISAKI ${ }^{1}$, KAZUE YOSHIHARA $^{1}$, ROPPEI YAMADA ${ }^{1}$, \\ NAOTO YAMAMOTO ${ }^{1}$, TSUTOMU SATO ${ }^{1}$, HIROCHIKA MAKINO ${ }^{1}$, SHIGERU YAMAGISHI $^{1}$, \\ YASUHIKO NAGANO ${ }^{1}$, SHOICH FUJII ${ }^{1}$, MANABU SHIOZAWA ${ }^{2}$, MAKOTO AKAIKE ${ }^{2}$, \\ NOBUYUKI WADA ${ }^{3}$, YASUSHI RINO ${ }^{3}$, MUNETAKA MASUDA $^{3}$, \\ KATSUAKI TANAKA $^{1}$ and TOSHIO IMADA ${ }^{4}$ \\ ${ }^{1}$ Gastroenterological Center, Yokohama City University Medical Center, 4-57 Urafune-cho, Minami-ku, \\ Yokohama-shi, Kanagawa-ken 232-0024; ${ }^{2}$ Department of Surgery, Kanagawa Cancer Center, 1-1-2 Nakao, \\ Asahi-ku, Yokohama-shi, Kanagawa-ken $241-0815 ;{ }^{3}$ Department of First Surgery; ${ }^{4}$ Yokohama City \\ University, 3-9 Fukuura, Kanazawa-ku, Yokohama-shi, Kanagawa-ken 236-0004, Japan
}

Received October 15, 2007; Accepted January 29, 2008

\begin{abstract}
Matrix metalloproteinase-2 (MMP-2), matrix metalloproteinase-9 (MMP-9) and membrane-type matrix metalloproteinase 1 (MT1-MMP) are involved in colorectal cancer invasion and metastasis. Reversion-inducing cysteinerich protein with Kazal motifs (RECK) inhibits MMP-2, MMP-9 and MT1-MMP. We examined the clinicopathological significance of the relative expression of these genes in patients with colorectal cancer, especially with regard to metastasis. We studied surgical specimens of cancer tissue and adjacent normal mucosa obtained from 205 patients with untreated colorectal carcinoma. MMP-2, MMP-9, MT1-MMP, RECK and $\beta$-actin mRNA of cancer tissue and adjacent normal mucosa were measured by quantitative real-time reverse-transcriptase polymerase chain reaction. $M T 1-M M P$ gene expression was higher in cancer tissue than in adjacent normal mucosa. In contrast, MMP-2, MMP-9 and RECK gene expression levels were lower in cancer tissue than in adjacent normal mucosa. As for the relationship between the gene expression and clinicopathological factors, $M M P-2$ expression
\end{abstract}

Correspondence to: Dr Takashi Oshima, Gastroenterological Center, Yokohama City University Medical Center, 4-57 Urafune-cho, Minami-ku, Yokohama-shi, Kanagawa-ken 232-0024, Japan

E-mail: ohshimatakashi@yahoo.co.jp

Key words: matrix metalloproteinase-2, matrix metalloproteinase-9, membrane-type matrix metalloproteinase 1, Kazal motifs, colorectal cancer correlated with the depth of invasion, venous invasion and liver metastasis; $M M P-9$ and RECK expression correlated with venous invasion. There were positive correlations among the gene expression levels of $M M P-2, M M P-9$ and $R E C K$. $M M P-2$ gene expression was considered a useful predictor of liver metastasis from colorectal cancer.

\section{Introduction}

Colorectal cancer, one of the most prevalent cancers worldwide (1), is the second leading cause of cancer-related mortality in developed countries (2). Tumor cell invasion and metastasis involve multiple steps, including proteolytic degradation of the basement membrane (BM) and extracellular matrix (ECM), altered cell adhesion and the physical movement of tumor cells. Among the many steps of tumor invasion and metastasis, excessive degradation of the matrix is one of the hallmarks of this process (3).

Matrix metalloproteinases (MMPs) are a key family of proteolytic enzymes involved in extracellular matrix degradation. In colorectal cancer, several MMPs have been found to be associated with tumor stage, prognosis, or both (4). Matrix metalloproteinase-2 (MMP-2) and matrix metalloproteinase-9 (MMP-9) have been implicated in the progression, invasion and metastasis of colorectal cancer in animal models and patients (5). MMP-2 and MMP-9 can degrade denatured collagen and type IV, V, VII, IX and X collagens. Type IV collagen is particularly abundant in basement membranes. These gelatinases are now also thought to be involved in cell differentiation, apoptosis, angiogenesis, immune response and cancer cell growth (6). The reversion-inducing cysteine-rich protein with Kazal motifs (RECK) gene was originally 
Table I. PCR primers and conditions.

\begin{tabular}{|c|c|c|c|}
\hline Gene & Primer & Temperature (C) & Product size (bp) \\
\hline$M M P-2$ & $\begin{array}{l}\text { 5'-СССТСССТTCAACCATTCCC-3' } \\
\text { 5'-TTCCAGCAGACACCATCACC-3' }\end{array}$ & 55.6 & 186 \\
\hline$M M P-9$ & $\begin{array}{l}\text { 5'-TGGTCCTGGTGCTCCTGGTG-3' } \\
\text { 5'-GCTGCCTGTCGGTGAGATTGG-3' }\end{array}$ & 61.2 & 111 \\
\hline$M T 1-M M P$ & $\begin{array}{l}\text { 5'-AAGAGGAGAAGAGCAAACAG-3' } \\
\text { 5'-CGGTAGGCACTGAACTTG-3' }\end{array}$ & 55.1 & 91 \\
\hline RECK & $\begin{array}{l}\text { 5'-ACTGCCGAGAATACTGTCAAGCC-3' } \\
\text { 5'-ACTATCCGTTGGGTTCCTCATTGG-3' }\end{array}$ & 64.9 & 161 \\
\hline$\beta$-actin & $\begin{array}{l}\text { 5'-AGTTGCGTTACACCCTTTCTTGAC-3' } \\
\text { 5'-GCTCGCTCCAACCGACTGC-3' }\end{array}$ & 60.0 & 171 \\
\hline
\end{tabular}

discovered in an expression cloning screen designed to isolate the transformation of suppressor genes against activated ras oncogenes $(5,7,8)$. The RECK gene encodes a membraneanchored glycoprotein and is down-regulated during the malignant conversion of cells (9). Although RECK is widely expressed in normal tissues and non-neoplastic cell lines, its expression is strongly suppressed in oncogene-transformed fibroblasts and several tumor-derived cell lines $(9,10)$. RECK inhibits MMP-2, MMP-9 and membrane-type matrix metalloproteinase 1 (MT1-MMP) secretion and activity, suggesting that it participates in the regulation of MMPs and tumor invasiveness (11). RECK is also vital to developmental vasculogenesis and its down-regulation has been implicated in tumor angiogenesis and progression $(9,11,12)$.

In this study, we examined the clinicopathlogical significance of the relative expression of these genes in patients with colorectal cancer, especially with regard to metastasis.

\section{Materials and methods}

Patients and samples. We studied surgical specimens of cancer tissue and adjacent normal mucosa obtained from 205 patients with untreated colorectal carcinoma. The patients underwent surgery at the Yokohama City Medical Center, Gastroenterological Center and Kanagawa Cancer Center between 2002 and 2006. Informed consent was obtained from each patient and the Yokohama City Medical Center Committee and Kanagawa Cancer Center Committee approved the study. Each sample was embedded in O.C.T. compound (Sakura Finetechnical Co., Ltd., Tokyo) and stored at $-80^{\circ} \mathrm{C}$, immediately before use. The patients had no other form of malignancy. After examining the histopathological features of specimens stained with hematoxylin and eosin, sections including $>80 \%$ carcinoma cells were used for total RNA preparation.

Quantitative real-time reverse-transcriptase polymerase chain reaction $(P C R)$. Total RNA from colorectal cancer tissue and adjacent normal mucosa was prepared with the use of Trizol (Gibco, Life Tech, Gaithersburg, MD). cDNA was synthesized from $2 \mu \mathrm{g}$ of total RNA using an iScript cDNA synthesis kit (Bio-Rad Laboratories, Hercules, CA). After synthesis, the cDNA was diluted 1:4 with water and stored at $-20^{\circ} \mathrm{C}$ until use. Quantitative real-time PCR was performed with iQ SYBR-Green Supermix (Bio-Rad Laboratories). PCR reactions were carried out in a total volume of $15 \mu \mathrm{l}$, containing cDNA derived from $75 \mathrm{ng}$ of RNA, $0.27 \mu \mathrm{M}$ of each primer, $7.5 \mu 1$ of iQ SYBR-Green Supermix containing dATP, dCTP, dGTP and dTTP at a concentration of $400 \mu \mathrm{M}$ each and $50 \mathrm{U} / \mathrm{ml}$ of iTag DNA polymerase. The PCR consisted of $10 \mathrm{~min}$ at $94^{\circ} \mathrm{C}$ followed by 50 cycles of denaturation of the cDNA for $30 \mathrm{sec}$ at $94^{\circ} \mathrm{C}$, annealing for $30 \mathrm{sec}$ at an appropriate temperature according to Table I and a primer extension for $1 \mathrm{~min}$ at $72^{\circ} \mathrm{C}$, followed by $72^{\circ} \mathrm{C}$ for $10 \mathrm{~min}$. The PCR primer sequences of MMP-2, MMP-9, MT1-MMP, RECK and $\beta$-actin, used as an internal control are shown in Table I.

Statistical analysis. Associations of the gene expression levels of colorectal cancer with those of adjacent normal mucosa were evaluated by the Wilcoxon test. The relationship between the gene expression levels and potential explanatory variables, including age, gender, tumor size, histological type, depth of invasion, lymph node metastasis, location, lymphatic invasion, venous invasion and liver metastasis, were assessed with the $\chi^{2}$ test. Associations among variables were evaluated with the Mann-Whitney $\mathrm{U}$ test. Correlation coefficients between different variables were determined by a simple regression analysis. Statistical analyses were performed using Statview J 5.0 software (Abacus, CA). Two-sided $\mathrm{P}$-values were calculated and $\mathrm{P}$-values $<0.05$ were considered to indicate statistical significance.

\section{Results}

Comparison of MMP-2, MMP-9, MT1-MMP and RECK mRNA expression between colorectal cancer tissue and adjacent normal mucosa. MMP-2, MMP-9 and RECK gene expression levels were lower in cancer tissue than in adjacent normal mucosa ( $\mathrm{P}=0.004,0.001$ and 0.006; Fig. 1A, B and D). In contrast, $M T 1-M M P$ gene expression in cancer tissue was higher than that in adjacent normal mucosa ( $\mathrm{P}=0.038$; Fig. 1C).

Relationship between clinicopathological features to MMP-2, MMP-9, MT1-MMP and RECK gene expression levels. After 
A

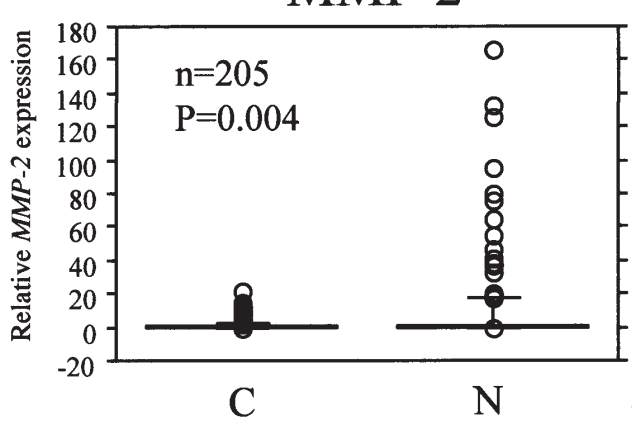

C

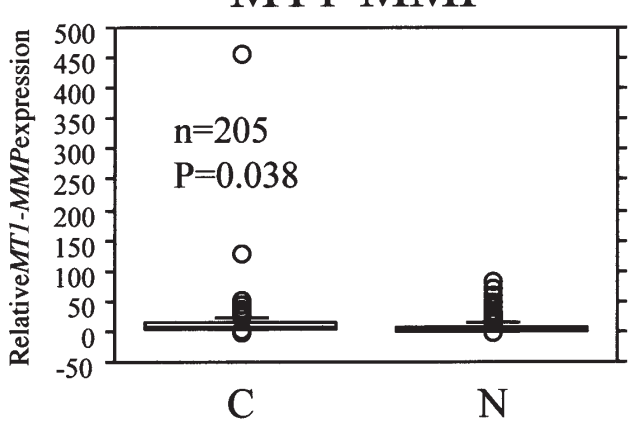

B

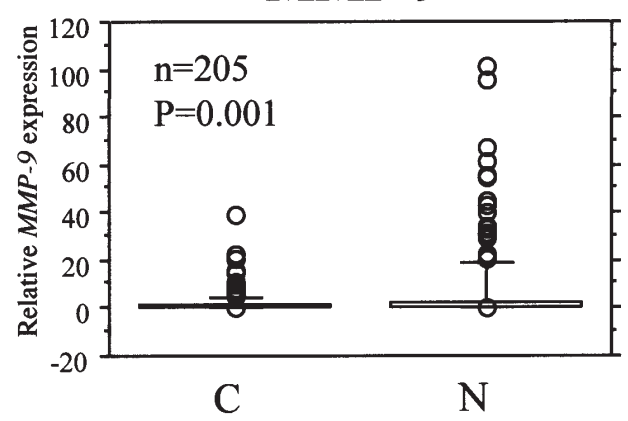

D

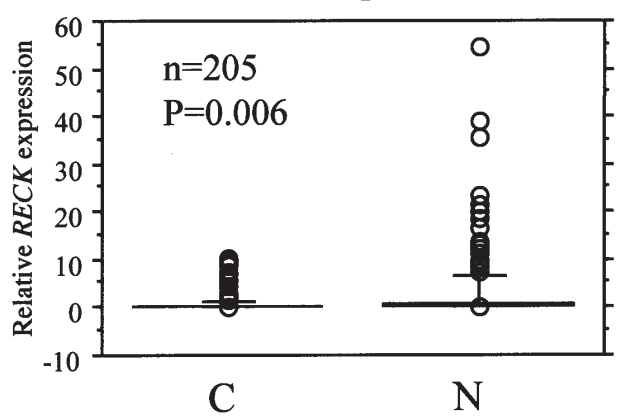

Figure 1. Comparison of $M M P-2, M M P-9, M T 1-M M P$ and $R E C K$ mRNA expression between colorectal cancer tissue and adjacent normal mucosa. $M M P-2$, $M M P-9$ and $R E C K$ gene expression levels were higher in adjacent normal mucosa than in cancer tissue $(\mathrm{P}=0.0462,0.0488$ and 0.0491$)$. However, the $M T 1-M M P$ gene expression level did not differ significantly between cancer tissue and adjacent normal mucosa.

A

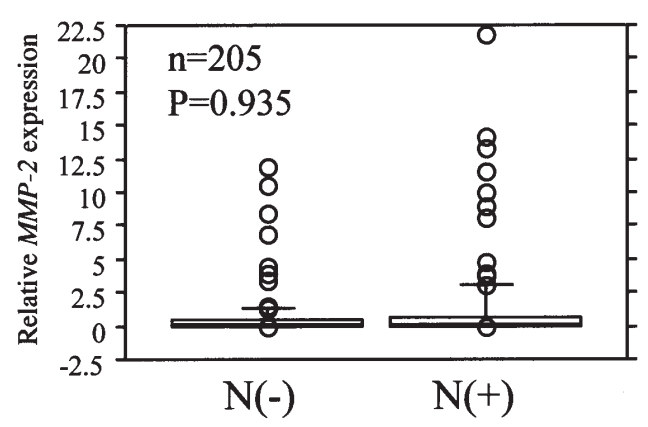

C

MT1-MMP

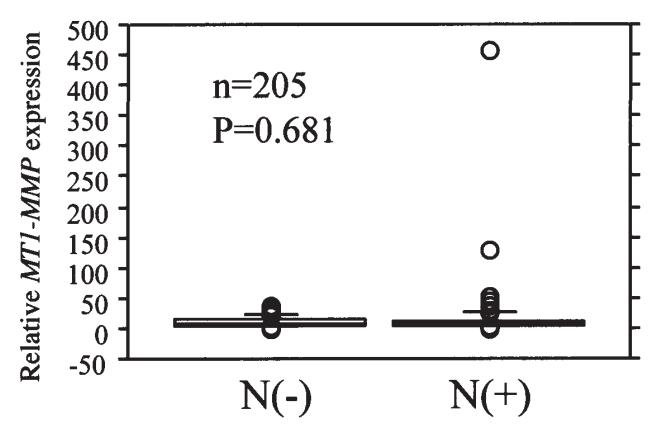

B MMP-9

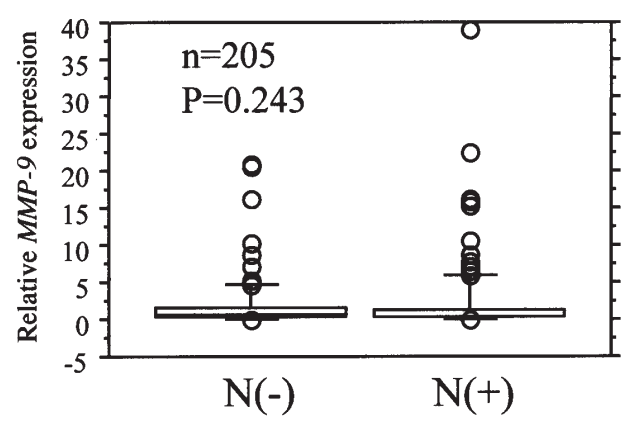

D

RECK

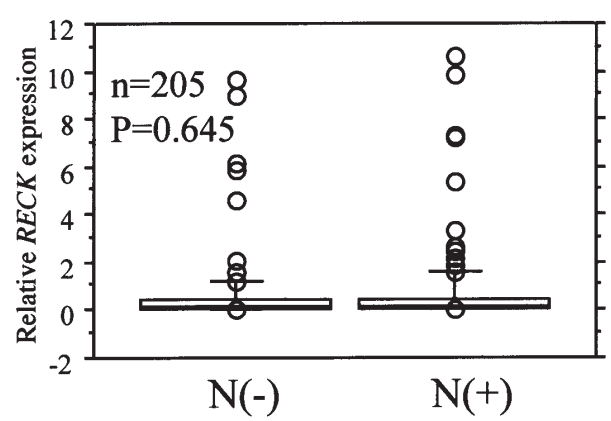

Figure 2. Association of $M M P-2, M M P-9, M T 1-M M P$ and $R E C K$ gene expression with lymph node metastasis in 205 patients with colorectal cancer. Box boundaries, the 25th and 75th percentiles of the observed values; capped bars, the 10th and 90th percentiles; solid line, the median. P-values were assessed by the Mann-Whitney U test. The presence or absence of lymph node metastasis was unrelated to the expression level of any gene. 


\section{A $\quad$ MMP-2}

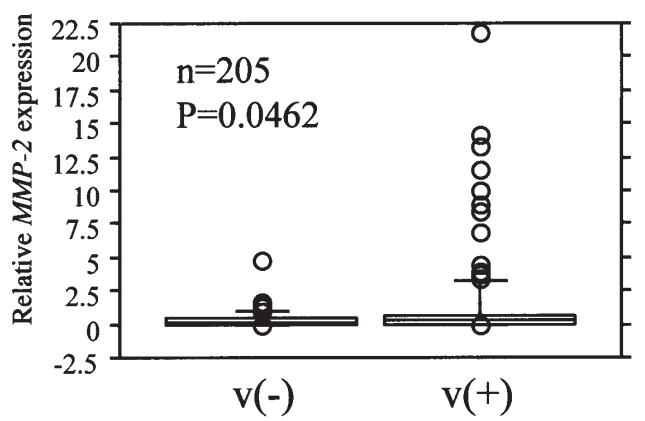

C MT1-MMP

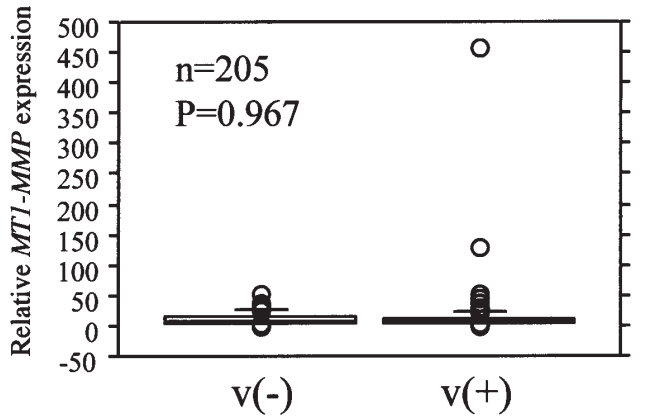

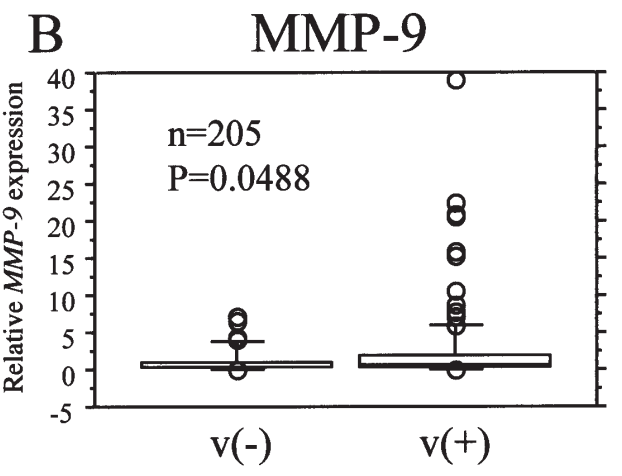

D RECK

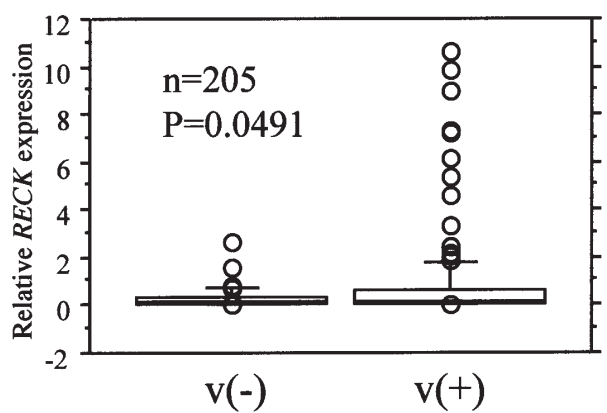

Figure 3. Association of $M M P-2, M M P-9, M T 1-M M P$ and $R E C K$ gene expression with venous invasion in 205 patients with colorectal cancer. Box boundaries, the 25th and 75th percentiles of the observed values; capped bars, the 10th and 90th percentiles; solid line, the median. P-values were assessed by the Mann-Whitney U test. The presence and absence of venous invasion was significantly related to the gene expression levels of $M M P-2, M M P-9$ and $R E C K$.

A

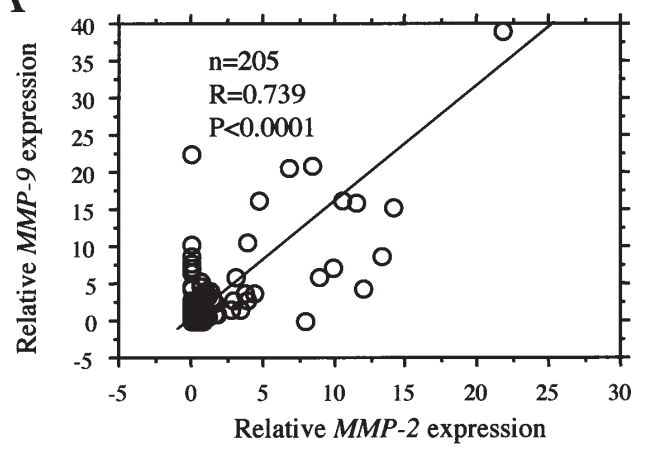

C

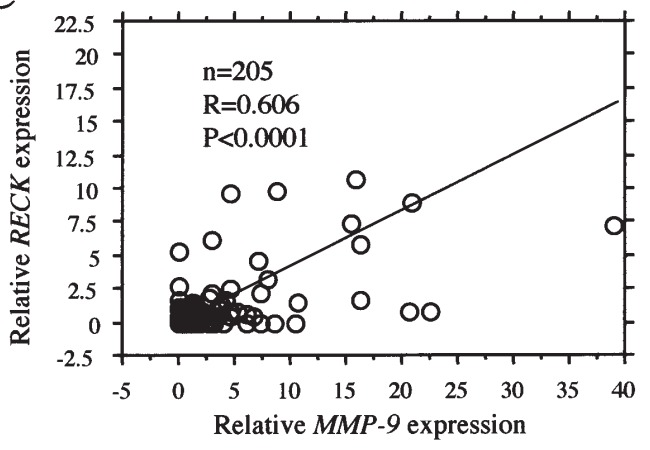

categorizing expression levels of $M M P-2, M M P-9, M T 1-M M P$ and $R E C K$ genes as low or high according to their respective median values, we examined the relationship between the expression levels of each gene and clinicopathological
B

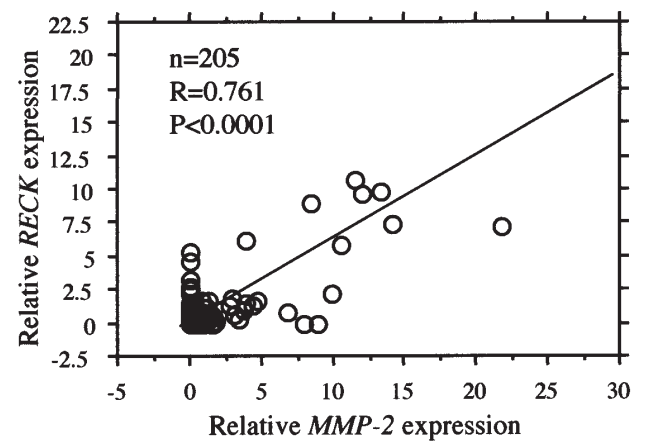

Figure 4. Correlation among gene expression levels of $M M P-2, M M P-9$ and $R E C K$ in colorectal cancers. Each gene expression level is relative to that of the $\beta$-actin gene. Correlations were observed between the gene expression levels of $M M P-2$ and $M M P-9(\mathrm{R}=0.739), M M P-2$ and $R E C K(\mathrm{R}=0.761)$ and $M M P-9$ and $R E C K(\mathrm{R}=0.606)$.

features. MMP-2, MMP-9, MT1-MMP and RECK gene expression levels were unrelated to age, gender, tumor size, histological type, lymph node metastasis, tumor location and lymphatic invasion. $M M P-2$ expression was significantly 


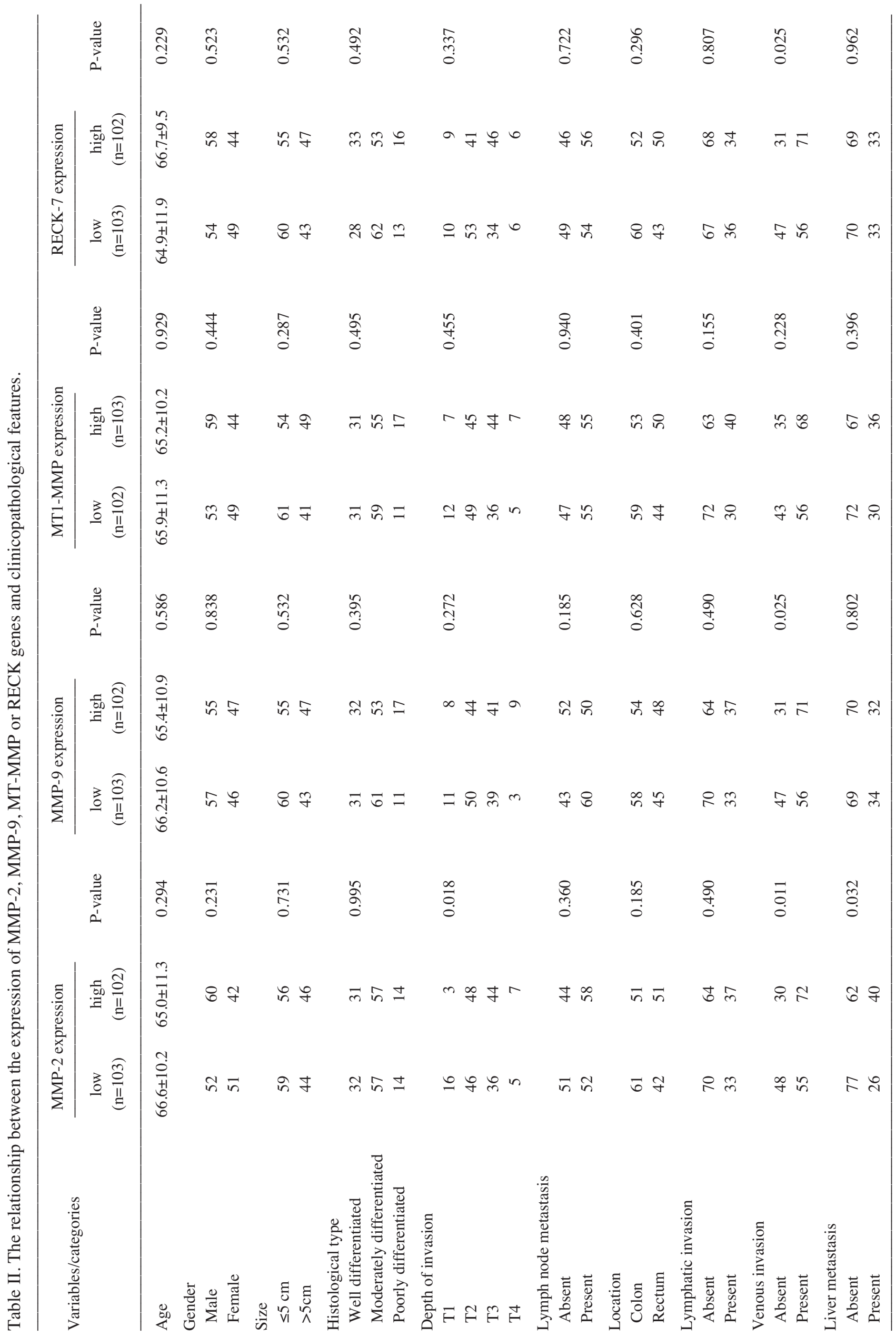


related to the depth of invasion $(\mathrm{P}=0.018) . M M P-2, M M P-9$, and $R E C K$ gene expression levels were significantly related to venous invasion $(\mathrm{P}=0.011,0.025$ and 0.035$) . M M P-2$ expression was also significantly related to liver metastasis $(\mathrm{P}=0.032$ ) (Table II).

Comparison of MMP-2, MMP-9, MT1-MMP and RECK gene expression levels according to the presence and absence of lymph node metastasis. There were no significant differences in $M M P-2, M M P-9, M T 1-M M P$ and RECK gene expression levels according to the presence or absence of lymph node metastasis (Fig. 2).

Comparison of MMP-2, MMP-9, MT1-MMP and RECK gene expression levels according to the presence or absence of venous invasion. MMP-2, MMP-9 and RECK gene expression levels differ significantly according to the presence or absence of venous invasion ( $\mathrm{P}=0.0462,0.0488$ and 0.0491$)$ (Fig. 3).

Correlation among MMP-2, MMP-9 and RECK expression. The results of a correlation analysis are shown in Fig. 4. Correlations were observed between the gene expression levels of $M M P-2$ and $M M P-9(\mathrm{R}=0.739), M M P-2$ and $R E C K$ $(\mathrm{R}=0.761)$ and $M M P-9$ and $R E C K(\mathrm{R}=0.606)$ (Fig. 4).

\section{Discussion}

MMP-2 and MMP-9 play key roles in the development and progression of human malignancies (13-15). These matrix metalloproteinases mediate the destruction of extracellular matrix and are considered an important early step in tumor invasion and metastasis. MMP-2 and MMP-9 also have angiogenic activity and participate in early tumorigenesis and tumor growth, including metastasis $(16,17)$. The overexpression of MT1-MMP in tumor cells promotes growth (18). The RECK gene is believed to regulate multiple MMP family members, such as MMP-2, MMP-9 and MT1-MMP (12).

Several previous studies have compared $M M P-2, M M P-9$, $M T 1-M M P$ and RECK mRNA expression levels between colorectal cancer tissue and adjacent normal mucosa. Kim et al (19) reported that $M M P-2$ and $M M P-9$ gene expression levels $(n=24)$ are higher in colorectal cancer than in adjacent normal mucosa. Lubbe et al (20) found that the MMP-9 gene expression level in colorectal cancer $(n=28)$ is higher than that in adjacent normal mucosa. However, in our study $(\mathrm{n}=205)$, $M M P-2, M M P-9$ gene expression levels were higher in adjacent normal mucosa than in cancer tissue. We believe that this result was related to the higher expression of MMP-2 and MMP-9 in interstitial tissues than in cancer cells. Atkinson et al (21) showed that the MT1-MMP gene expression level is higher in cancer tissue than in adjacent normal mucosa, while Takeuchi et al (22) reported that the RECK gene expression level is higher in adjacent normal mucosa than in colorectal cancer. In our study, RECK gene expression levels were higher in adjacent normal mucosa than in cancer tissue. Conversely, the MT1-MMP gene expression level was higher in cancer tissue than in adjacent normal mucosa.

Zheng et al (23) studied the relationship between the clinicopathological features and gene expression levels of MMPs. The expression levels of MMP-2 and MMP-9 were found to be closely linked to venous and lymph node invasion. Ogata et al (24) reported that MMP-9 expression is related to lymph node metastasis and severe venous invasion. Takeuchi et al (22) reported that RECK expression is significantly associated with lymph node metastasis, Dukes' stage and venous invasion. In our study, $M M P-2$, $M M P-9$ and $R E C K$ expression levels were significantly related to venous invasion. $M M P-2$ expression was also significantly related to tumor depth and liver metastasis. MT1-MMP has been reported to specifically activate MMP-2 (25). The association of $M M P-2$ expression with tumor depth, venous invasion and liver metastasis may be related to the finding that the $M T 1-M M P$ gene expression level was higher in cancer tissue than in adjacent normal mucosa in our study.

In a study examining interrelations among RECK, MMP-2, and MMP-9, van der Jagt et al found that RECK expression levels strongly correlate with the inhibition of MMP-2 enzyme activity, though not with the inhibition of MMP-9 activity (26). Masui et al reported a significant negative correlation between RECK activation and MMP-2 activation (27). In our study, correlations were observed between gene expression levels of RECK and $M M P-2, R E C K$ and $M M P-9$ and $M M P-2$ and $M M P-9$. These results demonstrated a positive correlation between the expression of $R E C K$ and $M M P-2$ at the mRNA level, although RECK inhibited MMP-2 activity at the enzyme level.

In conclusion, our study showed that $M M P-2, M M P-9$ and $R E C K$ gene expression levels were higher in adjacent normal mucosa than in cancer tissue and correlated with each other. Expression levels of these genes were significantly related to venous invasion. $M M P-2$ gene expression is considered a useful predictor of liver metastasis from colorectal cancer.

\section{References}

1. Jemal A, Murray T, Ward E, et al: Cancer statistics. CA Cancer J Clin 55: 10-30, 2005.

2. Greenwald P: Colon cancer overview. Cancer 70: 1206-1215, 1992.

3. Liotta LA and Stetler-Stevenson WG: Tumor invasion and metastasis: an imbalance of positive and negative regulation. Cancer Res 51: 5054-5059, 1991.

4. Wagenaar-Miller RA, Gorden L and Matrisian LM: Matrix metalloproteinases in colorectal cancer: is it worth talking about? Cancer Metastasis Rev 23: 119-135, 2004.

5. Noda M, Kitayama H, Matsuzaki T, et al: Detection of genes with a potential for suppressing the transformed phenotype associated with activated ras genes. Proc Natl Acad Sci USA 86: 162-166, 1989.

6. Mook OR, Frederiks WM, Van C and Noorden J: The role of gelatinases in colorectal cancer progression and metastasis. Biochim Biophys Acta 1705: 69-89, 2004.

7. Kitayama H, Sugimoto Y, Matsuzaki T, Ikawa Y and Noda M: A ras-related gene with transformation suppressor activity. Cell 56: 77-84, 1989

8. Takahashi C, Akiyama N, Matsuzaki T, Takai S, Kitayama H and Noda M: Characterization of a human MSX-2 cDNA and its fragment isolated as a transformation suppressor gene against v-Ki-ras oncogene. Oncogene 12: 2137-2146, 1996.

9. Takahashi C, Sheng Z, Horan TP, et al: Regulation of matrix metalloproteinase- 9 and inhibition of tumor invasion by the membrane-anchored glycoprotein RECK. Proc Natl Acad Sci USA 95: 13221-13226, 1998 .

10. Sasahara RM, Takahashi C and Noda M: Involvement of the Sp1 site in ras-mediated downregulation of the RECK metastasis suppressor gene. Biochem Biophys Res Commun 264: 668-675, 1999.

11. Oh J, Takahashi R, Kondo S, et al: The membrane-anchored MMP inhibitor RECK is a key regulator of extracellular matrix integrity and angiogenesis. Cell 107: 789-800, 2001. 
12. Weaver VM: Membrane-associated MMP regulators: novel cell adhesion tumor suppressor proteins? Dev Cell 2: 6-7, 2002.

13. Stetler-Stevenson WG: Type IV collagenases in tumor invasion and metastasis. Cancer Metastasis Rev 9: 289-303, 1990.

14. Liotta LA and Stetler-Stevenson WG: Metalloproteinases and cancer invasion. Semin Cancer Biol 1: 99-106, 1990.

15. Chambers AF and Matrisian LM: Changing views of the role of matrix metalloproteinases in metastasis. J Natl Cancer Inst 89: 1260-1270, 1997.

16. Jadhav U, Chigurupati S, Lakka SS and Mohanam S: Inhibition of matrix metalloproteinase-9 reduces in vitro invasion and angiogenesis in human microvascular endothelial cells. Int J Oncol 25: 1407-1414, 2004

17. Folgueras AR, Pendas AM, Sanchez LM and Lopez-Otin C: Matrix metalloproteinases in cancer: from new functions to improved inhibition strategies. Int J Dev Biol 48: 411-424, 2004.

18. Hotary KB, Allen ED, Brooks PC, Datta NS, Long MW and Weiss SJ: Membrane type I matrix metalloproteinase usurps tumor growth control imposed by the three-dimensional extracellular matrix. Cell 114: 33-45, 2003.

19. Kim TD, Song KS, Li G, et al: Activity and expression of urokinase-type plasminogen activator and matrix metalloproteinases in human colorectal cancer. BMC Cancer 6: 211, 2006.

20. Lubbe WJ, Zhou ZY, Fu W, et al: Tumor epithelial cell matrix metalloproteinase 9 is a target for antimetastatic therapy in colorectal cancer. Clin Cancer Res 12: 1876-1882, 2006.
21. Atkinson JM, Pennington CJ, Martin SW, et al: Membrane type matrix metalloproteinases (MMPs) show differential expression in non-small cell lung cancer (NSCLC) compared to normal lung: Correlation of MMP-14 mRNA expression and proteolytic activity. Eur J Cancer 43: 1764-1771, 2007.

22. Takeuchi $\mathrm{T}$, Hisanaga $\mathrm{M}$, Nagao $\mathrm{M}$, et al: The membraneanchored matrix metalloproteinase (MMP) regulator RECK in combination with MMP-9 serves as an informative prognostic indicator for colorectal cancer. Clin Cancer Res 10: 5572-5579, 2004.

23. Zheng H, Takahashi H, Murai Y, et al: Expressions of MMP-2, MMP-9 and VEGF are closely linked to growth, invasion, metastasis and angiogenesis of gastric carcinoma. Anticancer Res 26: 3579-3583, 2006

24. Ogata Y, Matono K, Sasatomi T, et al: The MMP-9 expression determined the efficacy of postoperative adjuvant chemotherapy using oral fluoropyrimidines in stage II or III colorectal cancer. Cancer Chemother Pharmacol 57: 577-583, 2006.

25. Sato H, Takino T, Okada Y, et al: A matrix metalloproteinase expressed on the surface of invasive tumor cells. Nature 370 61-65, 1994.

26. van der Jagt MF, Sweep FC, Waas ET, et al: Correlation of reversion-inducing cysteine-rich protein with kazal motifs (RECK) and extracellular matrix metalloproteinase inducer (EMMPRIN), with MMP-2, MMP-9, and survival in colorectal cancer. Cancer Lett 237: 289-297, 2006.

27. Masui T, Doi R, Koshiba T, et al: RECK expression in pancreatic cancer: its correlation with lower invasiveness and better prognosis. Clin Cancer Res 9: 1779-1784, 2003. 